\title{
The role of transient receptor potential vanilloid type-2 ion channels in innate and adaptive immune responses
}

\section{Giorgio Santoni ${ }^{1}{ }^{*}$, Valerio Farfariello ${ }^{1,2}$, Sonia Liberati ${ }^{1,3}$, Maria B. Morelli ${ }^{1}$, Massimo Nabissi ${ }^{1}$, Matteo Santoni ${ }^{4}$ and Consuelo Amantini ${ }^{1}$}

1 Section of Experimental Medicine, School of Pharmacy, University of Camerino, Camerino, Italy

2 Department of Urology and Andrology, University of Perugia, Perugia, Italy

${ }^{3}$ Department of Molecular Medicine, Sapienza University of Rome, Rome, Italy

${ }^{4}$ Department of Medical Oncology, Polytechnic University of the Marche Region, Ancona, Italy

\section{Edited by:}

Masaaki Murakami, Osaka University, Japan

\section{Reviewed by:}

Daisuke Kamimura, Osaka University, Japan

Hideki Ogura, Osaka University, Japan

*Correspondence:

Giorgio Santoni, Section of

Experimental Medicine, School of

Pharmacy, University of Camerino,

Via Madonna delle Carceri 9

62032 Camerino, Italy.

e-mail: giorgio.santoni@unicam.it
The transient receptor potential vanilloid type-2 (TRPV2), belonging to the transient receptor potential channel family, is a specialized ion channel expressed in human and other mammalian immune cells. This channel has been found to be expressed in CD34 ${ }^{+}$ hematopoietic stem cells, where its cytosolic $\mathrm{Ca}^{2+}$ activity is crucial for stem/progenitor cell cycle progression, growth, and differentiation. In innate immune cells, TRPV2 is expressed in granulocytes, macrophages, and monocytes where it stimulates fMet-LeuPhe migration, zymosan-, immunoglobulin G-, and complement-mediated phagocytosis, and lipopolysaccharide-induced tumor necrosis factor-alpha and interleukin-6 production. In mast cells, activation of TRPV2 allows intracellular $\mathrm{Ca}^{2+}$ ions flux, thus stimulating protein kinase A-dependent degranulation. In addition, TRPV2 is highly expressed in CD56 ${ }^{+}$natural killer cells. TRPV2 orchestrates $\mathrm{Ca}^{2+}$ signal in T cell activation, proliferation, and effector functions. Moreover, messenger RNA for TRPV2 are expressed in $\mathrm{CD}^{+}$and $\mathrm{CD}^{+} \mathrm{T}$ lymphocytes. Finally, TRPV2 is expressed in CD19+ $\mathrm{B}$ lymphocytes where it regulates $\mathrm{Ca}^{2+}$ release during $\mathrm{B}$ cell development and activation. Overall, the specific expression of TRPV2 in immune cells suggests a role in immune-mediated diseases and offers new potential targets for immunomodulation.

Keywords: transient receptor potential, transient receptor potential vanilloid type-2, macrophages, mastocytes, $T$ cell activation, $B$ cell activation, immuno-mediated-diseases, immunomodulation

\section{TRPV2: A MEMBER OF THE TRP CHANNEL FAMILY}

The 30 mammalian transient receptor potential (TRP) cation channels identified so far can be sorted into seven subfamilies: TRPC (canonical), TRPM (melastatin), TRPV (vanilloid), TRPA (ankyrin transmembrane protein), TRPP (polycystin), TRPML (mucolipin), and TRPN (NomPC-like). TRPs are essentially classified according to their primary amino acid sequence rather than selectivity or ligand affinity. From a structural standpoint, TRP channels are membrane proteins with six putative transmembrane spans (TMs) and a cation-permeable pore region formed by a short hydrophobic stretch between TM5 and TM6 (Owsianik et al., 2006; Figure 1). TRP proteins are essentially cation-permeable ion channels sensitive to a remarkable range of stimuli. Genetic approaches in worms, flies, and mice have demonstrated the involvement of TRPs in a variety of sensory processes that include thermosensation, osmosensation, olfaction, taste, mechanosensation, vision, and pain perception. Remarkably, mutations in different TRPs have also been linked to human diseases (Nilius et al., 2007).

Among TRPV channels, TRPV2 is a non-selective cation channel showing $\mathrm{Ca}^{2+}$ permeability (Caterina et al., 1999). Its activation triggers an inward cation current (mainly $\mathrm{Ca}^{2+}$ ) that mediates a relatively broad repertoire of physiological functions in response to noxious heat, with an activation threshold of $>52^{\circ} \mathrm{C}$, as well as to changes in osmolarity and membrane stretch. Human TRPV2 (hTRPV2) channel is triggered by agonists such as
$\Delta^{9}$-tetrahydrocannabinol $\left(\Delta^{9}-\mathrm{THC}\right)$ and cannabidiol (CBD; Neeper etal., 2007; Qin etal., 2008; Nabissi et al., 2013). It was found to be expressed both in the plasma membrane and early endosome. Activation of TRPV2 by growth factors causes PI-3K-dependent and independent translocation in the plasma membrane (Kanzaki et al., 1999; Penna et al., 2006). In addition, TRPV2 may serve as an endosomal calcium release channel that controls endosome fusion and/or exocytosis (Saito et al., 2007; Abe and Puertollano, 2011). It has been demonstrated that TRPV2 expression and activity are increased following inflammation, by the action of growth factors such as insulin-like growth factor I (IGF-I; Shimosato et al., 2005). However, the contribute of TRPV2 to inflammation requires further investigations.

This work summarizes data reported in the literature on the expression and function of TRPV2 in hematopoietic stem cells (HSCs) and in natural and adaptive immune cells (Table 1).

\section{EXPRESSION OF TRPV2 IN HSCs}

Stem cells are found in all multi-cellular organisms and are characterized by the ability to self-renew through mitotic cell division and differentiate into a range of specialized cell types. Multiple functional ion channel currents have been reported to be heterogeneously present in different types of stem cells. They include the voltage-gated delayed rectifier $\mathrm{K}^{+}$current (IKDR), the $\mathrm{Ca}^{2+}$-activated $\mathrm{K}^{+}$current $(\mathrm{KCa})$, inward rectifier $\mathrm{K}^{+}$current, 


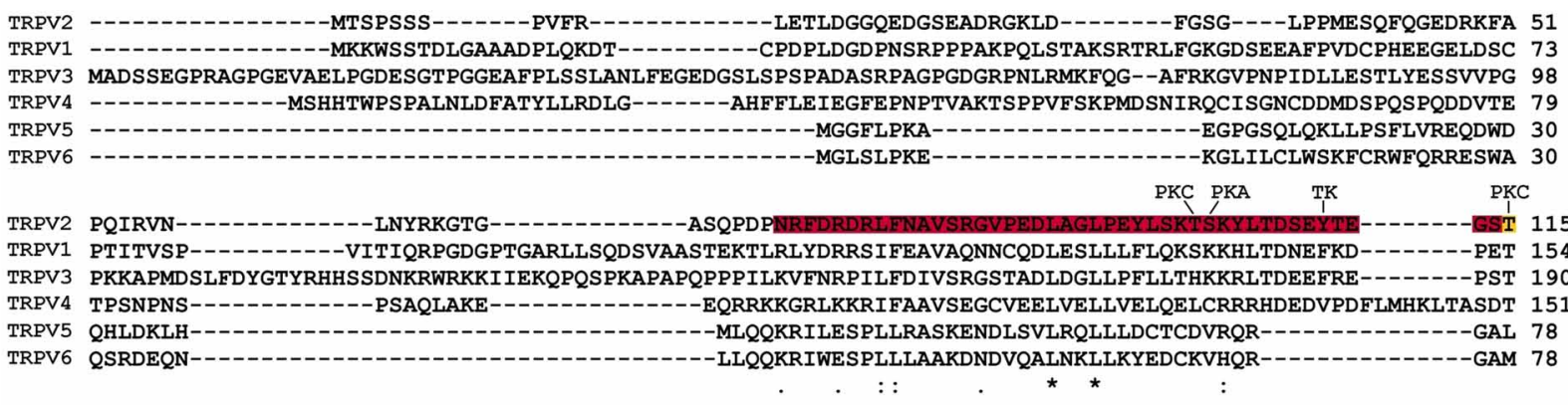

TRPV2 GKTCLMKAVLNLKDGVNACILPLLQIDRDSGNPQPLVNAQCTDDYYRGHSALHIAIEKRSLQCVKLLVENGANVHARACGRFFQKGQG-TCFYFGELPLS 214 TRPV1 GKTCLLKAMLNLHDGQNTTIPLLLEIAROTDSLKELVNASYTDSYYKGQTALHIAIERRNMALVTLLVENGADVQAAAHGDFFKKTKGRPGFYFGELPLS 254 TRPV3 GKTCLPKALLNLSNGRNDTIPVLLDIAERTGNMREFINSPFRDIYYRGQTALHIAIERRCKHYVELLVAQGADVHAQARGRFFQPKDEGGYFYFGELPLS 290 TRPV4 GKTCLMKALLNINPNTKEIVRILLAFAEENNILGRF INAEYTEEAYEGQTALNIAIERRQGDIAALLIAAGADVNAHAKGAFFNPKYQHEGFYFGETPLA 251 TRPV5 GETALHIAALYDN---LEAALVLMEAAP------ELVFEPTTCEAFAGOTALHIAVVNONVNLVRALLTRRASVSARATGTAFRRSPR-NLIYFGEHPLS 168 TRPV6 GETALHIAALYDN---LEAAMVLMEAAP------ELVFEPMTSELYEGQTALHIAVVNQNMNLVRALLARRASVSARATGTAFRRSPC-NLIYFGEHPLS 168

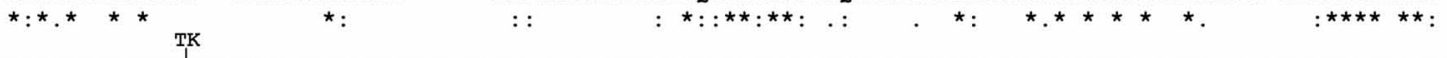

TRPV2 LAACTKQWDVVSYLLENPHQPASLQATDSQGNTVLHALVMISUNSAENIALVTSM TRPV1 LAACTNQLGIVKFLLQNSWQTADISARDSVGNTVLHALVEVADNTADNTKFVTSMYNEILMLGAKLHPTLKLEELTNKKGMTPLALAAGTGKIGVLAYIL 354 TRPV3 LAACTNQPHIVNYLTENPHKKADMRRQDSRGNTVLHALVAIADNTRENTKFVTKMYDLLLLKCARLFPDSNLEAVLNNDGLSPLMMAAKTGKIGIFQHII 390 TRPV4 LAACTNQPEIVQLIME--HEQTDITSRDSRGNNILHALVTVAEDFKTONDFVKRMYDMILLRSG----NWELETTRNNDGLTPLOLAAKMGKAEILKYIL 345 TRPV5 FAACVNSEEIVRLIIEH---GADIRAODSLGNTVLHILILQP-----NKTFACOMYNLLLSYDGHGDHLQPLDLVPNHOGLTPFKLAGVEGNTVMFOHLM 260 TRPV6 FAACVNSEEIVRLIIEH---GADIRAQDSLGNTVLHILILQP------NKTFACQMYNLILSYDRHGDHLQPLDLVPNHQGLTPFKLAGVEGNTVMFQHLM 260

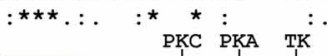

TRPV2 QREFSG--LSHLSRKFTEWCYGPVRVSLYDLASVDSC-EENSVLEIIAFH-CKSPHRHRMVVLEPLNKLLQAKWDLLIP-KFFLNFLCNLIYMFIFTAVA 409 TRPV1 QREIQEPECRHLSRKFTEWAYGPVHSSLYDLSCIDTC-EKNSVLEVIAYSSSETPNRHDMLLVEPLNRLLQDKWDRFVKRIFYFNFLVYCLYMIIFTMAA 453 TRPV3 RREVTDEDTRHLSRKFKDWAYGPVYSSLYDLSSLDTCGEEASVLEILVYN-SKIENRHEMLAVEPINELLRDKWRKFGAVSFYINVVSYLCAMVIFTLTA 489 TRPV4 SREIKEKRLRSLSRKFTDWAYGPVSSSLYDLTNVDTT-TDNSVLEITVYN-TNIDNRHEMLTLEPLHTLLHMKWKKFAKHMFFLSFCFYFFYNITLTLVS 443 TRPV5 Q---------KRRHIQWTYGPLTSILYDLTEIDSWGEELSFLELVVSS--DKREARQILEQTPVKELVSFKWNKYGRPYFCILAALYLLYMICFTTCC 347 TRPV6 Q--------KRKHTQWTYGPLTSTLYDLTEIDSSGDEQSLLELIITT--KKREARQILDQTPVKELVSLKWKRYGRPYFCMLGAIYLIYIICFTMCC 347

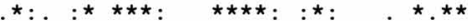

$$
\star:: \star * \star \quad * \text { * }
$$

TRPV2 YHQPTL--------------KKQAAPHLKAEVGNS--MLLTGHILILLGGIYLLVGQLW-YFWRRHV-FIWISFIDSYFEILFLFQALLTVVSQVLCFL 490 TRPV1 YYRP------------VDGLPPFKMEKTGDY--FRVTGEILSVLGGVYFFFRGIQ-YFLQRRP-SMKTLFVDSYSEMLFFLQSLFMLATVVLYFS 532 TRPV3 YYOP---------------LEGTPPYPYRTTVDY--LRLAGEVITLFTGVLFFFTNIKDLFMKKCP-GVNSLFIDGSFOLLYFIYSVVLVIVSAALYLA 569 TRPV4 YYRPR--------------EEEAIPHPLALTHKMGWLQLLGRMFVLIWAMCISVKEGIAIFLLRPS-DLQSILSDAWFHFVFFIQAVLVILSVFLYLF 526 TRPV5 VYRPLKFRGGNRTHSRDITILQQKLLQEAYETREDI--IRLVGELVSIVGAVIILLLEIPDIFRVGASRYFGKTILGGPFHVIIITYASLVLVTMVMRLT 445 TRPV6 IYRPLKPRTNNRTSPRDNTLLQOKLIQEAYMTPKDD--IRLVGELVTVIGAIIILLVEVPDIFRMGVTRFFGQTILGGPFHVLIITYAFMVLVTMVMRLI 445

$$
\therefore \text { * }
$$

TRPV2 AIEWYLPLLVSALVLGWLNLLYYTRGFQHTGIYSVMIQKVILRDLIRFLLIYLVFLFGFAVALVSLSQEAWRPEAPTGPNATESVQPMEGQEDEGNGAQY 590 TRPV1 HLKEYVASMVFSLALGWTNMLYYTRGFOOMGIYAVMIEKMILRDLCRFMFVYIVFLFGFSTAVVTLIEDGKNDSLPSESTSHRWRGPACRPPD----SSY 628 TRPV3 GIEAYLAVMVFALVLGWMNALYFTRGLKLTGTYSIMIQKILFKDLFRFLLVYLLFMIGYASALVSLLNPCANMKVCNEDQTNCTVPTYPSCRD-------S 663 TRPV4 AYKEYLACLVLAMALGWANMLYYTRGFQSMGMYSVMIQKVILHDVLKFLFVYIVFLLGFGVALASLIEKCPKDNKDCSS--

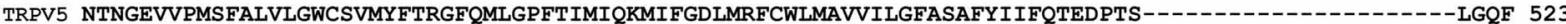
TRPV6 SASGEVVPMSFALVLGWCNVMYFARGFOMLGPFTIMIOKMIFGDLMRFCWLMAVVILGFASAFYIIFOTEDPEE---_-_-_-_-_-_-_-_-_--LGHF 523

TRPV2 RGILEASLELFKETIGMGEIAAFOEOLHFRGMVLLLLLAYVLLTYILLLNMLIALMSETVNSVATDSWSIWKLOKAISVLEMENGYWWCRKKO--------- 682 TRPV1 NSLYSTCLELFKFTIGMGDLEFTENYDFKAVFIILLLAYVILTYILLLNMLIALMGETVNKIAOESKNIWKLORAITILDTEKSFLKCMRKAF-------- 721 TRPV3 ETFSTFLLDLFKLTIGMGDLEMLSSTKYPVVFIILLVTYIILTFVLLLNMLIALMGETVGQVSKESKHIWKLQWATTILDIERSFPVFLRKAF-------- 756 TRPV4 GSFSDAVLELFKLTIGLGDLNIQQNSKYPILFLFLLITYVILTFVLLLNMLIALMGETVENVSKESERIWRLQRARTILEFEKMLPEWLRSRF-------- 699 TRPV5 YDYPMALFTTFELFLTVIDAPANYDVDLPFMFSIVNFAFAI IATLLMLNLFIAMMGDTHWRVAQERDELWRAQVVATTVMLERKLPRCLWPRSGICGCEF 623 TRPV6 YDYPMALFSTFELFLTIIDGPANYNVDLPFMYSITYAAFAIIATLLMLNLLIAMMGDTHWRVAHERDELWRAQIVATTVMLERKLPRCLWPRSGICGREY 623

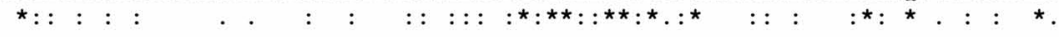

TRPV2 RAGVMLTVGTKPDGSPDERWCFRVEEVNWASWEOTLPTLCEDP-------SGAGVPRTLEN------------------PVLASPPKEDEDGASEENYVPV 758 TRPV1 RSGKLLQVGYTPDGKDDYRWCFRVDEVNWTTWNTNVGIINEDPG-----NCEGVKRTLSFSLRSSRVSGRHWKNFALVPLIREASARDRQSAQPEEVYLR 816 TRPV3 RSGEMVTVGKSSDGTPDRRWCFRVDEVNWSHWNQNLGIINEDPGKNETYQYYGFSHTVGRLRRDR----------WSSVVPRVVELNKNSNPDEVVVPL 845 TRPV4 RMGELCKVA------EDDFRLCLRINEVKWTEWKTHVSFLNEDPG---------PVRRTADFN----------------KIODSSRNNSKTTLNAFEEVE 768 TRPV5 GLGDRWFLRVENHNDQNPLRVLRYVEVFKNSDKEDDQEHPSEKQPSGAESGTLARASLALP-------------TSSLSRTASQSSSHRGWEILRQN 707 TRPV6 GLGDRWFLRVEDRQDLNRQRIQRYAQAFHTRGSEDLDKDSVEK----LELGCPFSPHLSLP----------------MPSVSRSTSRSSAN--WERLRQG 701 * : $\quad$ * :

TRPV2 QLLQSN-------------------- 764

TRPV1 QFSGSLKPEDAEVFKSPAASGEK--- 839

TRPV3 DSMGNPRCDGHOOGYPRKWRTDDAPI 871

TRPV4 EFPETSV----------------- 775

TRPV5 TLG-HLNLGLNLSEGDGE-EVYHF-- 729

TRPV6 TLRRDLRGIINRGLEDGESWEYQI-- 725

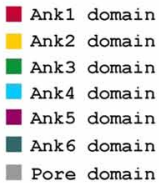

FIGURE 1 | Alignment and comparison of human TRPVs amino acid structure, highlighting the known functional domains and the potential phosphorylation sites. PKA, protein kinase A; PKC, protein kinase C; TK, tyrosine kinase. 
Table 1 | Role of TRPV2 in immune cells.

\begin{tabular}{llll}
\hline Cell type & Species & $\begin{array}{l}\text { TRPV2-mediated } \\
\text { effect }\end{array}$ & Reference \\
\hline Neutrophils & Human & Migration & Heiner et al. (2003) \\
Monocytes/ & Mouse & Migration & Nagasawa et al. (2007) \\
macrophages & & & \\
& Mouse & Phagocytosis & Link et al. (2010) \\
& Mouse & Cytokine production? & Yamashiro et al. (2010) \\
Mast cells & Mouse & Differentiation & Kajiya et al. (2010) \\
T cells & Human & Degranulation & Zhang et al. (2012) \\
& & T cell receptor and & Sauer and Jegla (2006) \\
& & & \\
& & &
\end{tabular}

hyperpolarization-activated cyclic nucleotide regulated cation current, chloride current, voltage-gated $\mathrm{Na}^{+}$current, L-type calcium current, and TRP non-selective cation currents ( $\mathrm{Li}$ and Deng, 2011).

While these channels are key players in the pathophysiology of excitable cells, a wide variety of ion channels are also expressed by non-excitable cells, such as cells of the immune system, where they function in signaling pathways regulating electrolyte transport, cell volume, proliferation, differentiation, and apoptosis.

CD34 ${ }^{+}$HSCs give rise to all types of blood cells from the myeloid (monocytes, neutrophils, erythrocytes, dendritic cells, etc.) and lymphoid lineages [T cells, B cells, and natural killer (NK) cells].

Cytosolic $\mathrm{Ca}^{2+}$ activity is crucial for stem/progenitor cell cycle progression and growth (Ferreira-Martins et al., 2009; Resende et al., 2010). Primary human CD34 ${ }^{+}$HSCs express voltage-gated $\mathrm{K}^{+}$channels, two-pore domain background $\mathrm{K}^{+}$channels, and TRP non-selective cation channel family. By using fluorescentactivated cell sorting (FACS) and reverse transcriptase-polymerase chain reaction (RT-PCR), it has been found that human $\mathrm{CD}^{+}{ }^{+} / \mathrm{CD} 45^{+} / \mathrm{CD} 133^{+} \mathrm{CD} 73^{-}$HSCs express TRPV2 channels (Park et al., 2011). Despite the limitation in applying higher temperature conditions, a $42^{\circ} \mathrm{C}$ TRPV2-like current was consistently observed in $\mathrm{CD}_{3}{ }^{+}$HSCs. These data are in accordance with the previously reported transcriptoma analysis evaluated by GNF gene expression (Su etal., 2004) suggesting a peculiar expression of TRPV2 mRNA in CD34 ${ }^{+}$HSCs (Figure 2). Recently, we have demonstrated, both at mRNA and protein levels, that human neural stem cells (NSCs) and glioblastoma stem-like cells (GSCs) express TRPV2 (Morelli et al., 2012), as reminiscence of the primitive myeloid progenitors (Ginhoux et al., 2010).

\section{TRPV2 CHANNELS IN CELLS OF NATURAL IMMUNITY}

Innate immunity, also called natural or native immunity, consists of cellular and biochemical defense mechanisms in place before infection and poised to respond rapidly to infections. The natural immune system includes cells of both myeloid and lymphoid origin, monocytes, macrophages, granulocytes, dendritic cells, and mastocytes as well as NK cells. These cells express many channels belonging to the TRP channel family. Among these, we focused our attention on the expression and function of TRPV2.

\section{GRANULOCYTES}

Immune cells kill microbes by engulfing them in a membraneenclosed compartment, the phagosome. Phagocytosis is initiated when foreign particles bind to receptors on the membrane of phagocytes. The best-studied phagocytic receptors, those for immunoglobulins $(\mathrm{F} c \gamma \mathrm{R})$ and for complement proteins (CR), activate phospholipase $\mathrm{C}$ (PLC) and $\mathrm{D}$ (PLD), resulting in the intracellular production of $\mathrm{Ca}^{2+}$. The molecules that mediate $\mathrm{Ca}^{2+}$ ion flux across the phagosomal membrane are still unknown but likely include the ubiquitous store-operated $\mathrm{Ca}^{2+}$ entry (SOCE) channels, ligand-gated chloride channel (LGCC), voltage-gated $\mathrm{Ca}^{2+}$ channel (VGCC), and TRP channels.

TRPV2 mRNA has been demonstrated in human neutrophil granulocytes by RT-PCR (Heiner et al., 2003). In these cells, TRPV2 seems to be of particular importance for the response to chemoattractants, suggesting a role in leukocyte migration.

\section{MONOCYTES AND MACROPHAGES}

TRPV2 gene expression data identify mRNA expression in human $\mathrm{CD}_{3}{ }^{+}$myeloid cells and $\mathrm{CD}_{1}{ }^{+}$monocytes. RT-PCR and immunoblot analyses have shown that TRPV2 is the sole member of the TRPV family expressed in mouse macrophages (Yamashiro et al., 2010), both in whole blood and in inflammatory tissues such as mouse peritoneal macrophages (Kim et al., 2003) and mouse osteoclasts (Kajiya et al., 2010). In addition, TRPV2 is expressed in human alveolar macrophages (Kowase et al., 2002).

It has been recently demonstrated (Nagasawa et al., 2007) that the chemotactic peptide fMet-Leu-Phe (fMLP) is able to promote the migration of mouse TtT/M87 macrophages by inducing the translocation of TRPV2 channels. This effect was blocked by an inhibitor of PI3-kinase, LY294002, and pertussis toxin. Moreover, treatment with serum-induced translocation of TRPV2 to the plasma membrane is blocked by transfection of short-form TRPV2 (s-TRPV2) lacking a pore-forming region and the sixth transmembrane domain. In experiments using whole-cell patch clamp, the $\mathrm{Ca}^{2+}$ current in TtT/M87 cells was blocked by the TRP channels inhibitor ruthenium red and transfection of either $s$ TRPV2 or siRNA for TRPV2. fMLP induced a rapid and sustained elevation of cytoplasmic $\mathrm{Ca}^{2+}$, that was abolished by removal of extracellular calcium, ruthenium red, and transfection of $s$ TRPV2 or siRNA-TRPV2. Finally, fMLP-induced migration of macrophages was blocked by ruthenium red or transfection of $s-T R P V 2$.

A role of TRPV2 in early phagocytosis and its fundamental importance in innate immunity was demonstrated in mice by Link et al. (2010). They showed that zymosan-, immunoglobulin G (IgG)-, and complement-mediated particle binding and phagocytosis were impaired in macrophages lacking TRPV2 channels. TRPV2 was recruited to the nascent phagosome and depolarized the plasma membrane. This event increased the synthesis of phosphatidylinositol 4,5-bisphosphate, which triggered partial actin depolymerization necessary for occupancy-elicited phagocytic receptor clustering (Figure 3 ). TRPV2-deficient macrophages 


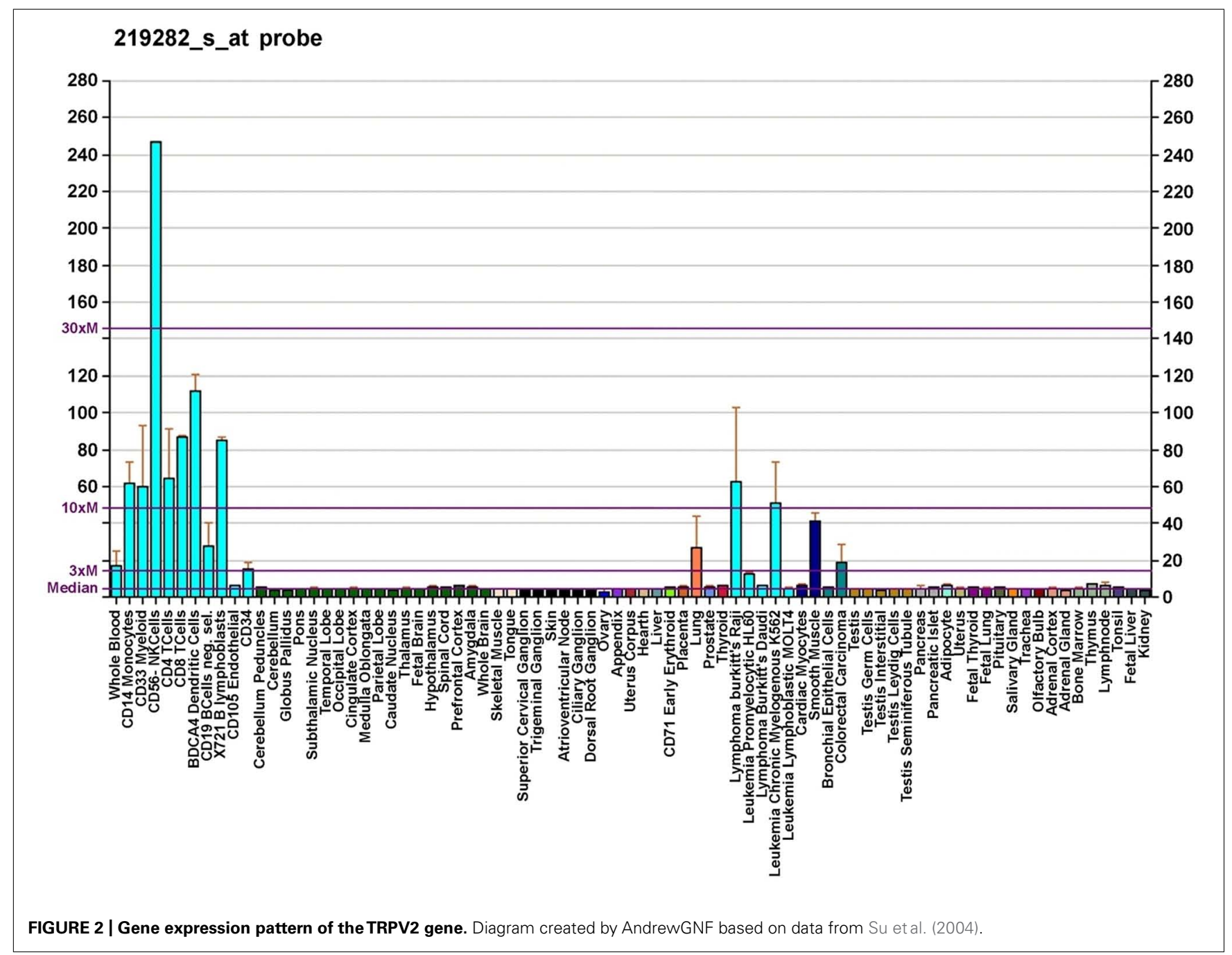

were also defective in chemoattractant-elicited motility. Finally, TRPV2-deficient mice showed accelerated mortality and greater organ bacterial load when challenged with Listeria monocytogenes.

Several studies have indicated that intracellular $\mathrm{Ca}^{2+}$ is a second messenger in Toll-like receptor 4 (TLR4)-dependent signaling. Recently, a role of TRPV2 in lipopolysaccharide (LPS)-induced cytokine mRNA production in mouse macrophages has been demonstrated (Yamashiro etal., 2010). Thus, shRNA against TRPV2 inhibited the LPS-induced mRNA for tumor necrosis factor-alpha (TNF- $\alpha$ ) and interleukin (IL)- 6 and induced inhibitor of nuclear factor-kappaB (NF- $\mathrm{KB})$ alpha $(\mathrm{IkB} \alpha)$ degradation. Experiments using 1,2-bis-(o-Aminophenoxy)-ethane$\mathrm{N}, \mathrm{N}, \mathrm{N}^{\prime}, \mathrm{N}^{\prime}$-tetraacetic acid, tetraacetoxymethyl ester (BAPTA/AM) and ethylene glycol tetraacetic acid (EGTA), and $\mathrm{Ca}^{2+}$ imaging indicated that LPS-induced increase in $\left[\mathrm{Ca}^{2+}\right] \mathrm{i}$ involves both TRPV2-mediated intracellular and extracellular $\mathrm{Ca}^{2+}$ mobilizations. In addition to $\mathrm{Ca}^{2+}$ mobilization through the IP3-receptor, TRPV2-mediated intracellular $\mathrm{Ca}^{2+}$ mobilization is involved in NF- $\kappa$ B-dependent TNF- $\alpha$ and IL- 6 expression, while extracellular

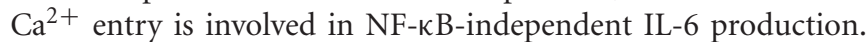
Another study carried out in TRPV2-knockout (KO) mice (Link et al., 2010) indicates that TRPV2 is not required for LPS-evoked TNF- $\alpha$ protein release. The discrepancy between these two studies could reside in the transcriptional (Yamashiro et al., 2010) or posttranscriptional mechanisms involved in the regulation of cytokine induction.

Recently, it has been demonstrated that the receptor activator of NF- $\mathrm{B}$ ligand (RANKL) induces TRPV2 expression and regulates mouse osteoclast differentiation (osteoclastogenesis) via calcium oscillations and activation of the nuclear factor of activated $\mathrm{T}$ cells 1 (NFATc1; Kajiya et al., 2010). $\mathrm{Ca}^{2+}$ oscillations are a prerequisite for NFAT-dependent transcription. A possible source of $\mathrm{Ca}^{2+}$ for calcineurin activation would be $\mathrm{Ca}^{2+}$ entry through TRP channels involved the so-called "store-operated $\mathrm{Ca}^{2+}$ entry." By using a DNA microarray, we found that TRPV2 channels are expressed significantly in RANKL-treated RAW264.7 cells (preosteoclasts) compared to untreated cells. RANKL up-regulates TRPV2 expression in preosteoclasts, evokes spontaneous $\mathrm{Ca}^{2+}$ oscillations, and a time-dependent transient inward cation current. The TRPV inhibitor ruthenium red and tetracycline-induced TRPV2 silencing decreased both the frequency of $\mathrm{Ca}^{2+}$ oscillations and transient inward currents in RANKL-treated preosteoclasts. Furthermore, 


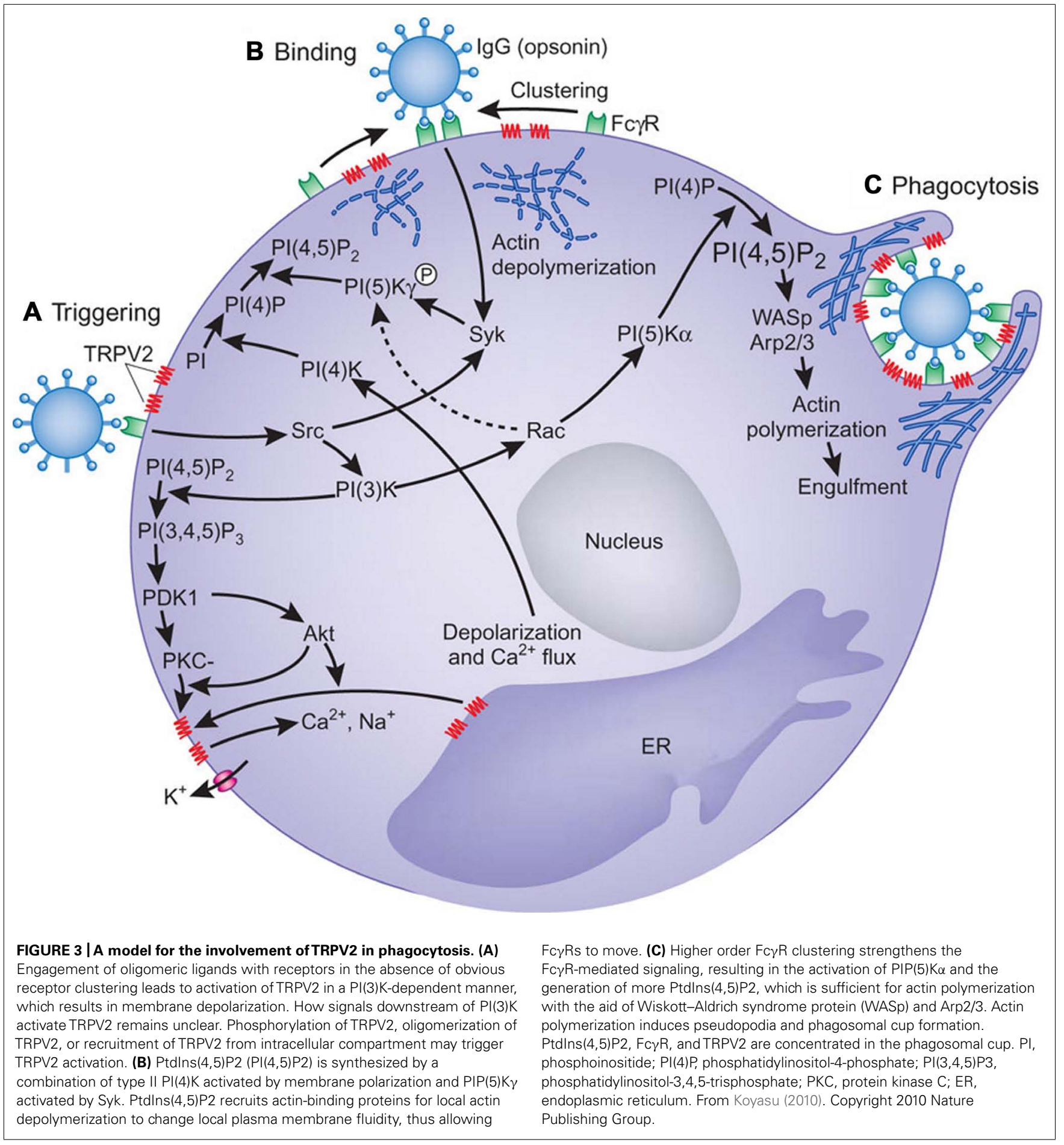

suppression of TRPV2 also reduced RANKL-induced NFATc1 expression, its nuclear translocation and osteoclastogenesis.

\section{DENDRITIC CELLS}

At present very few data have been provided on the expression of TRPV2 in dendritic cells in human. TRPV2 gene expression was identified in human dendritic cells, but no functional data have been provided so far (Su et al., 2004).

\section{NK CELLS}

TRPV2 gene is 10- to 30-fold more expressed in human CD56 ${ }^{+} \mathrm{NK}$ cells compared to all the other cells of both innate and adaptive systems (Su et al., 2004). Although this very high expression of TRPV2 in NK cells is of great interest, the role of these channels is still unknown. In rats, administration of $2.5 \mathrm{mg} / \mathrm{kg}$ of a TRPV2 agonist, CBD, increased the total number of NK cells and their percentage (Ignatowska-Jankowska et al., 2009). Finally, on the 
basis of Link et al. (2010) data obtained in mouse, a role of TRPV2 in natural and antibody-dependent cytotoxicity of NK cells may be hypothesized.

\section{MAST CELLS}

Mast cells are tissue-resident immune effector cells. They respond to diverse stimuli by releasing potent biological mediators into the surrounding tissue, and initiating inflammatory responses that promote wound healing and infection clearance. In addition to stimulation via immunological routes, mast cells also respond to polybasic secretagogues and physical stimuli. Each mechanism for mast cell activation relies on the influx of calcium through specific ion channels in the plasma membrane (Turner et al., 2007).

The expression, surface localization, and oligomerization of TRPV2 protein subunits together with functional coupling of TRPV2 protein to calcium fluxes and proinflammatory degranulation events have been reported in mast cells (Stokes et al., 2004; Freichel et al., 2012). In addition, a novel protein kinase A (PKA)-dependent signaling module containing PKA and a putative A kinase adapter protein, acyl CoA binding domaincontaining protein 3 (ACBD3), that interacts with TRPV2, has been demonstrated in human mast cells (Stokes et al., 2004).

A characteristic of TRPV2 is its activation by high noxious temperature; temperatures exceeding $50^{\circ} \mathrm{C}$ induced a ruthenium red-sensitive current. In addition, laser light of $640 \mathrm{~nm}$ or light at $48 \mathrm{~mW}$ for $20 \mathrm{~min}$ induced current sensitive to SKF96365, a selective inhibitor of receptor-mediated $\mathrm{Ca}^{2+}$ entry and voltage-gated $\mathrm{Ca}^{2+}$ entry. Thus, all the three physical stimuli able to activate the TRPV2 channel-induced pronounced degranulation in human mast cells, which could be blocked by ruthenium red or SKF96365. Activation of TRPV2 allows $\mathrm{Ca}^{2+}$ ions to enter the cell, which in turn induce degranulation, suggesting that TRPV2 plays a key role in mast cell degranulation in response to mechanical, heat, and red laser light stimulation (Zhang et al., 2012).

\section{TRPV2 CHANNELS IN ADAPTIVE IMMUNITY T LYMPHOCYTES}

Calcium acts as a second messenger in many cell types, including lymphocytes. Resting lymphocytes maintain a low concentration of $\mathrm{Ca}^{2+}$ (Cahalan and Chandy, 2009; Vig and Kinet, 2009). A network of six distinct types of ion channels, namely Kv1.3, KCa3.1, olfactory receptor class A related 1 (Orai1), stromal interacting molecule 1 (STIM1), $\mathrm{Ca}^{2+}$ release activating $\mathrm{Ca}^{2+}$ (CRAC) channel, TRPV7 and TRPV2, orchestrates T cell activation, proliferation, and effector functions, offering potential targets for immunomodulation (Sauer and Jegla, 2006; Cahalan and Chandy, 2009). Most recently, TRPV2 has been found to cluster at the immunological synapse following contact with antigen-presenting cells, together with Kv1.3, KCa3.1, STIM1, and Orail channels (Sauer and Jegla, 2006; Lioudyno et al., 2008; Cahalan and Chandy, 2009). In regard to TRPV2, Sauer and Jegla (2006) have reported that knockdown of TRPV2 in T cells impairs T cell receptor (TCR) and calcium signaling. Specifically, in Jurkat cells nucleofected with shDNA against hTRPV2, a defect in TCR or thapsigargininduced calcium mobilization, with predominant effect on the sustained phase of calcium influx, has been reported. Similar to the effect induced by the knockdown of Lck (lymphocyte-specific protein tyrosine kinase shDNA), an essential mediator of TCR signaling, hTRPV2 shDNA transfected cells displayed a reduction in store release, indicative of impaired conformational coupling between CRAC channels and IP3 receptors (Cui et al., 2002). In addition, dominant negative hTRPV2 inhibits endogenous channels mediating $\mathrm{Ca}^{2+}$ influx (Sauer and Jegla, 2006).

By quantitative RT-PCR (qRT-PCR), TRPV2 mRNA was detected in whole peripheral blood, primary human $\mathrm{T}$ cells (Saunders et al., 2007; Schwarz et al., 2007), CD4 ${ }^{+}$and $\mathrm{CD}^{+}$ $\mathrm{T}$ cells (Spinsanti et al., 2008). In rats, administration of the specific TRPV2 agonist, CBD, at a dose of $5 \mathrm{mg} / \mathrm{kg}$ caused a significant fall in $\mathrm{T}$ cells and $\mathrm{T}$ helper ( $\mathrm{Th}$ ) and cytotoxic T (Tc) lymphocyte subsets (Ignatowska-Jankowska et al., 2009). Moreover, CBD decreased the constitutive production of IL8 , macrophage inflammatory protein 1 alpha (MIP- $1 \alpha$ and $\beta$ ), and Rantes, and phorbol ester stimulated production of TNF$\alpha$, granulocyte-macrophage colony-stimulating factor (GM-CSF), and interferon-gamma (IFN- $\gamma$ ) by human NK cells (Srivastava et al., 1998). In addition, exposure of human T cells THC decreased steady-state levels of mRNA encoding for Th1 cytokines, while increasing mRNA levels for Th2 cytokines (Yuan et al., 2002).

\section{B LYMPHOCYTES}

At present, the literature offers very little information on the expression of TRPV2 $\mathrm{mRNA}$ and protein in human. Using GNF gene analysis, the expression of TRPV2 mRNA was found in whole blood, lymph nodes and tonsils, and human $\mathrm{CD} 19^{+} \mathrm{B}$ lymphocytes (Su et al., 2004). These data were recently confirmed by Boyd et al. (2009), who used qRT-PCR, immunofluorescence and FACS analysis to demonstrate both at mRNA and protein levels the expression of TRPV2 in normal human CD19+ $\mathrm{B}$ lymphocytes and $\mathrm{CD} 138^{+}$plasma cells.

Information about the expression and function of TRPV2 in B lymphocytes was provided by Kanzaki etal. (1999) on growth factor-regulated channel (GRC). It has been shown to be $79.4 \%$ identical to mouse TRPV2 (mTRPV2) at the amino-acidic sequence. GRC belongs to the TRP channel family (mTRPV2) localizes mainly in intracellular pools under basal conditions. Upon stimulation of cells by IGF-I, GRC translocates to the plasma membrane. Thus, IGF-I augments calcium entry through GRC by regulating trafficking of the channel (Kanzaki et al., 1999).

Overall, it is conceivable that TRPV2 acts as a transmembrane protein expressed on the surface of $\mathrm{B}$ cells, and that it negatively controls $\mathrm{Ca}^{2+}$ flux-activated proliferative signal transduction pathways and $\mathrm{B}$ cell activation at immunological synaptic level. Thus, the inhibitory role showed by TRPV2 in in vivo B cell number, could be the result of CBD-induced translocation of TRPV2 from the cytosol to the plasma membrane (Kanzaki et al., 1999; Ignatowska-Jankowska et al., 2009; Morelli et al., 2012). In the same view, the structural and functional similarity of mTRPV2 with CD20, a calcium permeable cation channel involved in B cell activation (Bubien et al., 1993; Tedder and Engel, 1994; Figure 4) and the inhibition of human embryonic kidney 293 (HEK-293) cell proliferation induced by TRPV2 transfection, further support this hypothesis (Penna et al., 2006; Nabissi et al., 2010).

It has also been suggested that TRPV2 plays an important role in regulating $\mathrm{Ca}^{2+}$ release during $\mathrm{B}$ cell development. Thus, the 
A

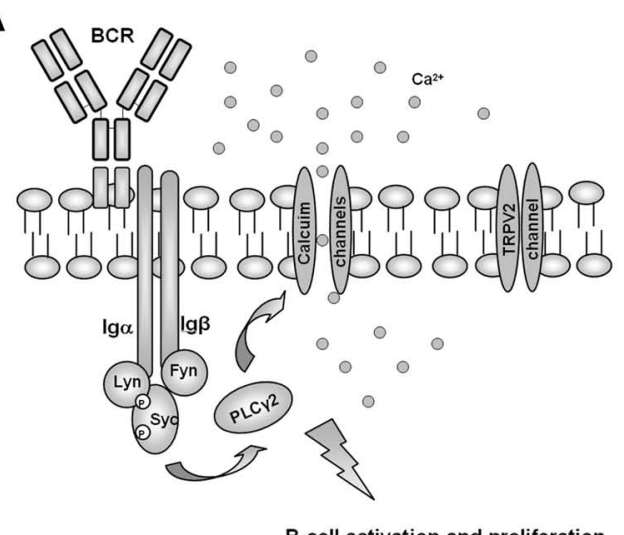

B-cell activation and proliferation

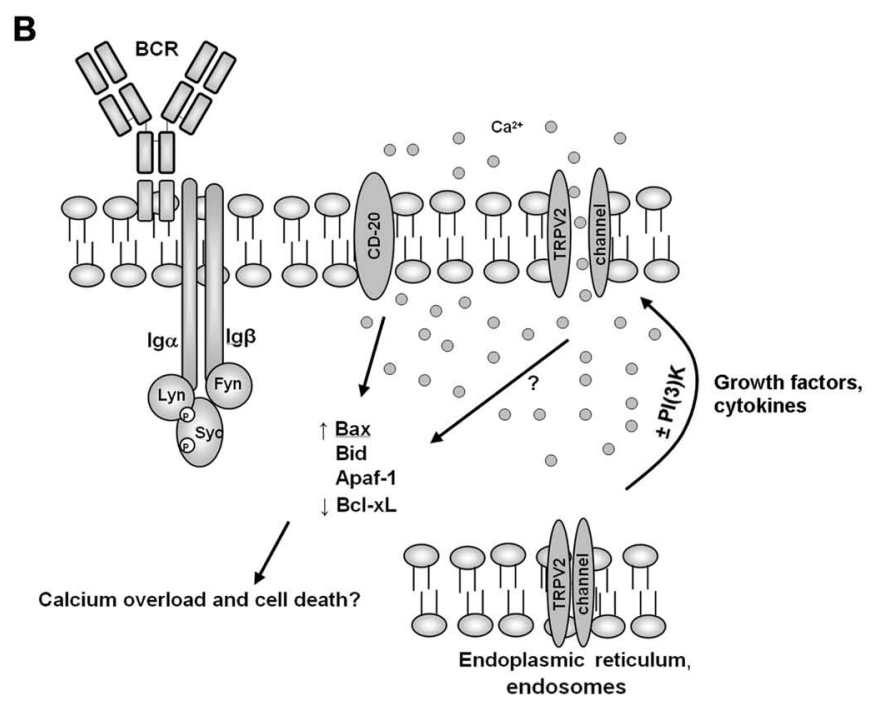

inducing PI(3)K-dependent or independent pathways, may induce TRPV2 translocation and activation, resulting in calcium overload, B cell activation shut-down and induction of pro-apoptotic cell death pathways, in a similar way to CD20. promoter of TRPV2 shows binding sites for regulatory transcription factors such as AP2rep, NF-AT1, NF-AT2, and NF-AT3 as well as for Bach-2 (Su et al., 2004), which is critical for class switch recombination and somatic hypermutation of immunoglobulin genes (Muto et al., 2004).

TRPV2 channel has been found to be associated with the recombinase gene activator protein during biosynthesis and early trafficking; it has been observed that over-expression of RGA protein potentiates basal surface localization of TRPV2 and cyclic adenosine monophosphate (cAMP) signal in human non-sensory cells (Barnhill et al., 2004; Stokes et al., 2005). In developing B cells, expression of surface immunoglobulin is an important signal to terminate recombinase activator gene (RAG) expression and $\mathrm{V}(\mathrm{D}) \mathrm{J}$ recombination. Cannabinoids play a critical role in B cell activation and maturation, and the direct role of these compounds in inducing $\mathrm{B}$ cell class switching from IgM to IgE has been demonstrated in mice (Agudelo et al., 2008), however, the role of TRPV2 has not been addressed so far.

\section{CONCLUSION}

The TRPV2 is a specialized ion channel expressed in mammalian innate and adaptive immune system. Recent findings on the TRPV2-mediated migration and phagocytosis of granulocytes and macrophages, PKA-dependent mast cell degranulation

\section{REFERENCES}

Abe, K., and Puertollano, R. (2011). Role of TRP channels in the regulation of the endosomal pathway. Physiology 26, 14-22.

Agudelo, M., Newton, C., Widen, R., Sherwood, T., Nong, L., Friedman, H., et al. (2008). Cannabinoid receptor 2 (CB2) mediates immunoglobulin class switching from IgM to IgE in culture of murine-purified B lymphocytes. J. Neuroimmune Pharmacol. 3, 35-42.

Barnhill, J. C., Stokes, A. J., KoblanMuraguchi, A., Adra, C. N., et al. (2004). RGA protein associates with a TRPV ion channel during Huberson, M., Shimoda, L. M.,

and its hypothesized role in NK cell cytotoxicity, strongly suggest a major role played by TRPV2 in the control of innate immune responses. Moreover, research on the involvement of TRPV2 as negative transductor in T and B cell activation is still at the beginning. One recent finding is the expression of TRPV2 in a chronic inflammatory skin diseases of unknown etiology called erythematotelangiectatic and papulopustular rosacea (Sulk et al., 2012).

Genetic approaches are required to advance a causal understanding on the role of TRPV2 in inflammatory immune-mediated diseases and cancer. These approaches include over-expression of dominant negative variants, antisense oligonucleotides, and siRNA.

Moreover, although the search for natural TRPV2 ligands and chemical modulators as therapeutic agents has been intensified in the last years (e.g., synthetic and endogenous cannabinoids), specific agonists or blockers and a specific monoclonal anti-hTRPV2 antibody are still lacking.

Further study should be performed to completely address the role of TRPV2 in the pathophysiology of the immune system.

\section{ACKNOWLEDGMENT}

This work was supported by the Associazione Italiana per la Ricerca sul Cancro (AIRC) National Grant 2011-2013 (Number 11095).

biosynthesis and trafficking. J. Cell. Biochem. 91, 808-820.

Boyd, R. S., Jukes-Jones, R., Walewska, R., Brown, D., Dyer, M. J., and Cain, K. (2009). Protein profiling of plasma membranes defines aberrant signaling pathways in mantle cell lymphoma. Mol. Cell. Proteomics 8, 1501-1515.
Bubien, J. K., Zhou, L. J., Bell, P. D., Frizzell, R. A., and Tedder, T. F. (1993). Transfection of the CD20 cell surface molecule into ectopic cell types generates a $\mathrm{Ca} 2+$ conductance found constitutively in B lymphocytes. J. Cell Biol. 121, 1121-1132.

Cahalan, M. D., and Chandy, K. G. (2009). The functional network 
of ion channels in $\mathrm{T}$ lymphocytes. Immunol. Rev. 231, 59-87.

Caterina, M. J., Rosen, T. A., Tominaga, M., Brake, A. J., and Julius, D. (1999). A capsaicin-receptor homologue with a high threshold for noxious heat. Nature 398, 436-441.

Cui, J., Bian, J. S., Kagan, A., and McDonald, T. V. (2002). CaT1 contributes to the storesoperated calcium current in Jurkat T-lymphocytes. J. Biol. Chem. 277, 47175-47183.

Ferreira-Martins, J., Rondon-Clavo, C., Tugal, D., Korn, J. A., Rizzi, R., Padin-Iruegas, M. E., et al. (2009). Spontaneous calcium oscillations regulate human cardiac progenitor cell growth. Circ. Res. 105, 764-774.

Freichel, M., Almering, J., and Tsvilovskyy, V. (2012). The role of TRP proteins in Mast cells. Front. Immunol. 3:150. doi: 10.3389/ fimmu.2012.00150

Ginhoux, F., Greter, M., Leboeuf, M., Nandi, S., See, P., Gokhan, S., etal. (2010). Fate mapping analysis reveals that adult microglia derive from primitive macrophages. Science 330, 841-845.

Heiner, I., Eisfeld, J., and Lückhoff, A. (2003). Role and regulation of TRP channels in neutrophil granulocytes. Cell Calcium 33, 533-540.

Ignatowska-Jankowska, B., Jankowski, M., Glac, W., and Swiergel, A. H. (2009). Cannabidiol-induced lymphopenia does not involve NKT and NK cells. J. Physiol. Pharmacol. 60, 99-103.

Kajiya, H., Okamoto, F., Nemoto, T., Kimachi, K., Toh-Goto, K., Nakayana, S., et al. (2010). RANKL-induced TRPV2 expression regulates osteoclastogenesis via calcium oscillations. Cell Calcium 48, 260-269.

Kanzaki, M., Zhang, Y. Q., Mashima, H., Li, L., Shibata, H., and Kojima, I. (1999). Translocation of a calcium-permeable cation channel induced by insulin-like growth factor-I. Nat. Cell Biol. 1, 165-170.

Kim, C. S., Kawada, T., Kim, B. S., Han, I. S., Choe, S. Y., Kurata, T., et al. (2003). Capsaicin exhibits antiinflammatory property by inhibiting IkB-a degradation in LPS-stimulated peritoneal macrophages. Cell. Signal. 15, 299-306.

Kowase, T., Nakazato, Y., Yoko-O, H., Morikawa, A., and Kojima, I. (2002). Immunohistochemical localization of growth factor-regulated channel (GRC) in human tissues. Endocr. J. 49, 349-355.
Koyasu, S. (2010). Vanilloid flavor for a good appetite? Nat. Immunol. 11, 187-189.

Li, G. R., and Deng, X. L. (2011). Functional ion channels in stem cells. World J. Stem Cells 3 19-24.

Link, T. M., Park, U., Vonakis, B. M., Raben, D. M., Soloski, M. J., and Caterina, M. J. (2010). TRPV2 has a pivotal role in macrophage particle binding and phagocytosis. Nat. Immunol. 11, 232-239.

Lioudyno, M. I., Kozak, J. A., Penna, A., Safrina, O., Zhang, S. L., Sen, D., et al. (2008). Orai and STIM1 move to the immunological synapse and are up-regulated during $\mathrm{T}$ cell activation. Proc. Natl. Acad. Sci. U.S.A. 105, 2011-2016.

Morelli, M. B., Nabissi, M., Amantini, C., Farfariello, V., Ricci-Vitiani, L., di Martino, S., et al. (2012). The transient receptor potential vanilloid-2 cation channel impairs glioblastoma stem-like cell proliferation and promotes differentiation. Int. J. Cancer 131, E1067-E1077.

Muto, A., Tashiro, S., Nakajima, O., Hoshino, H., Takahashi, S., Sakoda E., et al. (2004). The transcriptional programme of antibody class switching involves the repressor Bach2. Nature 429, 566-571.

Nabissi, M., Morelli, M. B., Amantini, C., Farfariello, V., Ricci-Vitiani, L., Caprodossi, S., et al. (2010). TRPV2 channel negatively controls glioma cell proliferation and resistance to Fas-induced apoptosis in ERK-dependent manner. Carcinogenesis 31, 794-803.

Nabissi, M., Morelli, M. B., Santoni, M., and Santoni, G. (2013). Triggering of the TRPV2 channel by cannabidiol sensitizes glioblastoma cells to cytotoxic chemotherapeutic agents. Carcinogenesis 34, 48-57.

Nagasawa, M., Nakagawa, Y., Tanaka, S., and Kojima, I. (2007). Chemotactic peptide fMetLeuPhe induces translocation of the TRPV2 channel in macrophages. J. Cell. Physiol. 210, 692-702.

Neeper, M. P., Liu, Y., Hutchinson, T. L., Wang, Y., Flores, C. M., and Qin, N. (2007). Activation properties of heterologously expressed mammalian TRPV2: evidence for species dependence. J. Biol. Chem. 282, 15894-15902.

Nilius, B., Owsianik, G., Voets, T., and Peters, J. A. (2007). Transient receptor potential cation channels in disease. Physiol. Rev. 87, 165-217.

Owsianik, G., D'Hoedt, D., Voets, T., and Nilius, B. (2006). Structurefunction relationship of the TRP channel superfamily. Rev. Physiol. Biochem. Pharmacol. 156, 61-90.

Park, K. S., Pang, B., Park, S. J., Lee, Y. G., Bae, J. Y., Park, S., et al. (2011). Identification and functional characterization of ion channels in CD34(+) hematopoietic stem cells from human peripheral blood. $\mathrm{Mol}$. Cells 32, 181-188.

Penna, A., Juvin, V., Chemin, J., Compan, V., Monet, M., and Rassendren, F. A. (2006). Pl3-kinase promotes TRPV2 activity independently of channel translocation to the plasma membrane. Cell Calcium 39, 495-507.

Qin, N., Neeper, M. P., Liu, Y., Hutchinson, T. L., Lubin, M. L., and Flores, C. M. (2008). TRPV2 is activated by cannabidiol and mediates CGRP release in cultured rat dorsal root ganglion neurons. J. Neurosci. 28, 6231-6238.

Resende, R. R., Adhikari, A., da Costa, J. L., Lorençon, E., Ladeira, M. S., Guatimosim, S., et al. (2010). Influence of spontaneous calcium events on cell-cycle progression in embryonal carcinoma and adult stem cells. Biochim. Biophys. Acta 1803 , 246-260.

Saito, M., Hanson, P. I., and Schlesinger, P. (2007). Luminal chloridedependent activation of endosome calcium channels. Patch clamp study of enlarged endosomes. J. Biol. Chem. 282, 27327-27333.

Sauer, K., and Jegla, T. J. (2006). Methods for Identifying T Cell Activa tion Modulating Compounds. Patent Application WO/2006/065613.

Saunders, C. I., Kunde, D. A., Crawford, A., and Geraghty, D. P. (2007). Expression of transient receptor potential vanilloid 1 (TRPV1) and 2 (TRPV2) in human peripheral blood. Mol. Immunol. 44, 1429-1435. Schwarz, E. C., Wolfs, M. J., Tonner, S., Wenning, A. S., Quintana, A. Griesemer, D., et al. (2007). TRP channels in lymphocytes. Handb. Exp. Pharmacol. 179, 445-456.

Shimosato, G., Amaya, F., Ueda, M., Tanaka, Y., Decosterd, I., and Tanaka, M. (2005). Peripheral inflammation induces up-regulation of TRPV2 expression in rat DRG. Pain 119, 225-232.

Spinsanti, G., Zannolli, R., Panti, C., Ceccarelli, I., Marsili, L., Bachiocco, V., et al. (2008). Quantitative realtime PCR detection of TRPV1-4 gene expression in human leukocytes from healthy and hyposensitive subjects. Mol. Pain 4, 51.

Srivastava, M. D., Srivastava, B. I., and Brouhard, B. (1998). Delta9 tetrahydrocannabinol and cannabidiol alter cytokine production by human immune cells. Immunopharmacology 40, 179-185.

Stokes, A. J., Shimoda, L. M., KoblanHuberson, M., Adra, C. N., and Turner, H. (2004). TRPV2-PKA signaling module for transduction of physical stimuli in mast cells. J. Exp. Med. 200, 137-147.

Stokes, A. J., Wakano, C., Del Carmen, K. A., Koblan-Huberson, M., and Turner, H. (2005). Formation of a physiological complex between TRPV2 and RGA protein promotes cell surface expression of TRPV2. J. Cell. Biochem. 94, 669-683.

Su, A. I., Wiltshire, T., Batalov, S., Lapp, H., Ching, K. A., Block, D., et al. (2004). A gene atlas of the mouse and human protein-encoding transcriptomes. Proc. Natl. Acad. Sci. U.S.A. 101, 6062-6067.

Sulk, M., Seeliger, S., Aubert, J., Schwab, V. D., Cevikbas, F., Rivier, M., et al. (2012). . Distribution and expression of non-neuronal transient receptor potential (TRPV) ion channels in rosacea. J. Invest. Dermatol. 132, 1253-1262.

Tedder, T. F., and Engel, P. (1994). CD20: a regulator of cell-cycle progression of B lymphocytes. Immunol. Today 15, 450-454.

Turner, H., del Carmen, K. A., and Stokes, A. (2007). Link between TRPV channels and mast cell function. Handb. Exp. Pharmacol. 179, 457-471.

Vig, M., and Kinet, J. P. (2009). Calcium signaling in immune cells. Nat. Immunol. 10, 21-27.

Yamashiro, K., Sasano, T., Tojo, K., Namekata, I., Kurokawa, J., Sawada, N., etal. (2010). Role of transient receptor potential vanilloid 2 in LPS-induced cytokine production in macrophages. Biochem. Biophys. Res. Commun. 398, 284-289.

Yuan, M., Kiertscher, S. M., Cheng, Q., Zoumalan, R., Tashkin, D. P., and Roth, M. D. (2002). Delta 9-tetrahydrocannabinol regulates Th1/Th2 cytokine balance in activated human T cells. J. Neuroimmunol. 133, 124-131.

Zhang, D., Spielmann, A., Wang, L., Ding, G., Huang, F., Gu, Q., et al. (2012). Mast-cell degranulation induced by physical stimuli involves the activation of transient-receptorpotential channel TRPV2. Physiol. Res. 61, 113-124.

Conflict of Interest Statement: The authors declare that the research was conducted in the absence of any commercial or financial relationships that 
could be construed as a potential conflict of interest.

Received: 13 December 2012; paperpending published: 06 January 2013; accepted: 30 January 2013; published online: 14 February 2013.
Citation: Santoni G, Farfariello V, Liberati S, Morelli MB, Nabissi M, Santoni $M$ and Amantini $C$ (2013) The role of transient receptor potential vanilloid type-2 ion channels in innate and adaptive immune responses. Front. Immun. 4:34. doi: 10.3389/fimmu.2013.00034
This article was submitted to Frontiers in Inflammation, a specialty of Frontiers in Immunology.

Copyright (c) 2013 Santoni, Farfariello, Liberati, Morelli, Nabissi, Santoni and Amantini. This is an open-access article distributed under the terms of the
Creative Commons Attribution License, which permits use, distribution and reproduction in other forums, provided the original authors and source are credited and subject to any copyright notices concerning any third-party graphics etc. 